\title{
Secrets of the lac Operon
}

\section{Glucose Hysteresis as a Mechanism in Dietary Restriction, Aging and Disease}

\author{
Charles V. Mobbs, Jason W. Mastaitis, Minhua Zhang, \\ Fumiko Isoda, Hui Cheng, Kelvin Yen \\ Departments of Neuroscience and Geriatrics, Mount Sinai School of Medicine, \\ New York, N.Y., USA
}

\begin{abstract}
Elevated blood glucose associated with diabetes produces progressive and apparently irreversible damage to many cell types. Conversely, reduction of glucose extends life span in yeast, and dietary restriction reduces blood glucose. Therefore it has been hypothesized that cumulative toxic effects of glucose drive at least some aspects of the aging process and, conversely, that protective effects of dietary restriction are mediated by a reduction in exposure to glucose. The mechanisms mediating cumulative toxic effects of glucose are suggested by two general principles of metabolic processes, illustrated by the lac operon but also observed with glucose-induced gene expression. First, metabolites induce the machinery of their own metabolism. Second, induction of gene expression by metabolites can entail a form of molecular memory called hysteresis. When applied to glucose-regulated gene expression, these two principles suggest a mechanism whereby repetitive exposure to postprandial excursions of glucose leads to an age-related increase in glycolytic capacity (and reduction in $\beta$-oxidation of free fatty acids), which in turn leads to an increased generation of oxidative damage and a decreased capacity to respond to oxidative damage, independent of metabolic rate. According to this mechanism, dietary restriction increases life span and reduces pathology by reducing exposure to glucose and therefore delaying the development of glucose-induced glycolytic capacity.
\end{abstract}

Copyright $(C) 2007$ S. Karger AG, Basel

Masoro et al. [1] proposed that 'dietary restriction retards the aging processes by altering the characteristics of fuel use'. Similarly, on the basis of a large-scale analysis of gene expression, Lee et al. [2] concluded that 'aging was associated with transcriptional alterations consistent with a metabolic shift from fatty acid to carbohydrate metabolism' and that dietary restriction 
'resulted in alterations in gene expression consistent with preserved fatty acid metabolism' through 'transcriptional reprogramming' (see also Anderson and Weindruch in this volume). Indeed, life span in yeast is increased simply by reducing glucose concentrations which, interestingly, actually increases metabolic rate [3]. In the present review we extend these concepts and propose a specific mechanism by which a cumulative toxic effect of glucose drives at least some aspects of the aging process, reduction in which mediates protective effects of dietary restriction.

\section{Glucose Increases Glycolysis and Inhibits Alternative Metabolic Pathways, Including $\beta$-Oxidation of Free Fatty Acids}

A general feature of metabolic regulation is that substrates typically induce the metabolic machinery necessary for their own metabolism. The classic example of this phenomenon is the lac operon, in which lactose induces both the activity and gene expression of $\beta$-galactosidase, the rate-limiting enzyme for the degradation of lactose [4]. In yeast, whose natural history entails cyclic utilization of glucose followed by ethanol as energy sources, glucose depletion inhibits glycolysis and activates the pathways for ethanol metabolism [5]. In mammals, glucose induces the coordinated expression of glycolytic enzymes including phosphofructokinase, the rate-limiting enzyme for glycolysis [6]. Conversely, glucose inhibits the expression of pyruvate dehydrogenase kinase 4 (PDK-4), which is an inhibitor of pyruvate dehydrogenase [7]. Thus glucose induces the utilization of glucose carbons in both glycolysis and in the tricarboxylic acid cycle. In insulin-sensitive tissues, glucose acts in concert with insulin to increase glycolytic activity [8]. Cognate induction of its own metabolism is particularly salient for glucose, probably because, as the unique product of photosynthesis and the ultimate source of biological energy, metabolism of glucose has been particularly optimized through evolution. Thus, although lactose induces the lac operon, the lac operon is robustly inhibited by a similar concentration of glucose. Similar glucose repression of alternative metabolic pathways is observed in yeast $[5,9]$ and fungi $[10]$. As with the lac operon, induction of glycolytic capacity by glucose is accompanied by suppression of the utilization of alternate fuels such as oxidation of fatty acids [11]. It should be noted that fatty acids conversely induce the metabolic machinery for their own metabolism, especially through the regulation of members of the peroxisomal proliferator receptor family of transcription factors, which by inducing PDK-4 [7] can conversely reduce pyruvate dehydrogenase activity and therefore glucose metabolism. Thus in mammals glucose and free fatty acids are constantly engaged in substrate competition. 


\section{Metabolic Regulation of Gene Expression Exhibits Hysteresis}

Of particular relevance to aging, the effects of metabolites on their own metabolic fate may not be entirely reversible, i.e. metabolic reprogramming may exhibit hysteresis. Hysteresis refers to a phenomenon by which a system exhibits memory. For example, a classic example of hysteresis is the Schmidt trigger switch encountered in electrical engineering. If the switch is off and the voltage increases from 0 to $5 \mathrm{mV}$, for example, the switch is not activated until reaching $5 \mathrm{mV}$. However, if the trigger begins in the activated position at $5 \mathrm{mV}$ and voltage decreases from 5 to $0 \mathrm{mV}$, the switch does not turn off until the voltage reaches $0 \mathrm{mV}$. Therefore at $3 \mathrm{mV}$, the trigger will be either on or off, depending on the history of the circuit. Although not as widely appreciated, gene expression also exhibits hysteresis, also sometimes called 'gene memory' or 'priming' [12-16]. For example, the first time the ovalbumin gene is exposed to estrogen the induction is sluggish and subtle, but subsequent exposures to estrogen produce much more rapid and robust inductions, a phenomenon associated with permanent changes in chromatin structure produced by the initial exposure to estrogen [17]. Indeed, 'cellular memory' has been invoked to describe the phenomenon of permanent change in gene expression after transient exposure to inducers during development [18]. Metabolic regulation of gene expression also exhibits hysteresis. For example, induction of the lac operon exhibits a history-dependent dose dependency that is precisely analogous to a Schmidt trigger [19,20]. Thus if the system begins with the lac operon inactive at low levels of inducer, the operon does not become active until exposed to high levels of inducer. On the other hand, if the system begins with the lac operon active at high levels of inducer, it stays active until exposed to very low levels of inducer. Thus, depending on the history of the system, the operon would be either on or off at modest levels of inducer. In fact, this behavior has led investigators to refer to the lac operon as a multistable 'switch' [19, 20].

Accumulating evidence suggests that the regulation of gene expression by glucose and other factors also exhibits hysteresis [15]. For example, glucoseinduced expression of fibronectin appears to be remarkably persistent even after reduction of glucose concentration [21]. Furthermore, it is increasingly clear that deleterious effects of elevated glucose persist for years after correction of blood glucose in diabetes [22]. As described below, based on our analysis of glucose-regulated gene expression and studies of the mechanism of neuroendocrine glucose sensing, we propose that hysteresis of glucose-regulated gene expression entails persistent self-induction of cytoplasmic NADH, the signature metabolite of glycolysis. 


\section{Mitochondrial Complex II Promotes Longevity, Other Mitochondrial Complexes Reduce Longevity}

The fact that diabetes accelerates many age-related pathologies, especially cardiovascular pathologies, suggests that diabetes and aging may share common pathological mechanisms. Certainly this is clear for yeast, in which reducing glucose concentration is sufficient to increase life span [3]. A role for glucose metabolism in determining life span is also suggested by examination of the role of specific complexes of the mitochondrial electron transport chain (ETC) in determining longevity. Genome-wide screening studies have demonstrated that genes coding for mitochondrial functions constitute possibly the most conspicuous single class of 'senescence assurance genes', ablation of which increases life span [23, 24]. Almost all of these life-span-limiting mitochondrial genes code for proteins in mitochondrial complexes I, III, IV or V [23-26]. For example, of 23 genes discovered in an exhaustive genome-wide screen whose inhibition increased life span [26], 12 were genes coding for proteins in mitochondrial (ETC) complexes I, III, IV or V, and one gene coded for a key enzyme in glycolysis, glucose-6-phosphate isomerase. An independent screen from another laboratory obtained very similar results, though discovering a different glycolytic enzyme whose inhibition increases life span [25]. Strikingly absent from these screens were genes for proteins in mitochondrial complex II [25, 26]. Indeed, classic genetic screens had already identified that mutations causing impairments in complex II reduce life span [27]. Thus proteins in mitochondrial complexes I, III, IV and V and at least some glycolytic enzymes function to limit life span, whereas genes for proteins in mitochondrial complex II function to increase life span. As described below, this pattern also implicates glucose in regulating life span, because glucose catabolism preferentially utilizes complex I, whereas lipid catabolism preferentially utilizes complex II.

\section{Complex II Produces Fewer Reactive Oxygen Species than Other Complexes}

The effects of mitochondrial impairments to increase life span are not due to reduced production of ATP (oxidative phosphorylation) since mutations in complex II function to reduce respiratory function [28], as do impairments in complexes I, III, IV and V [23]. Conversely, other studies demonstrate that simply reducing production of ATP is not sufficient to increase life span [23]. In fact, in yeast, reducing exposure to glucose increased metabolic rate while also increasing longevity [3]. The most likely mechanism for the striking dichotomy of mitochondrial complex function with respect to life span is that reactive 
oxygen species are normally produced in complex I, III, IV and V, but much less so in complex II [29-31]. This basic fact about mitochondrial function explains why inactivating mutations in complex II produce profound sensitivity to oxidative damage as well as reduced life span [28, 32]. They also suggest the hypothesis that disruption of mitochondrial complexes I, III, IV and V increase life span by producing a relative increase in the utilization of complex II over the other complexes. While such a pattern of fuel use might or might not reduce ATP synthesis, the actual mechanism extending life span would be, according to this hypothesis, reduced production of reactive oxygen species due to relatively increased utilization of complex II.

\section{Reduced Complex I Activity Is Associated with Increased Life Span in Worms, Mice and Humans}

As indicated above, genome-wide screening revealed that RNA-interferencemediated reduction in complex I activity increases life span in Caenorhabditis elegans [25, 26]. Furthermore, classic genetic screens had previously identified that mutations in the $c l k-1$ gene [33], which also influences mitochondrial function [34], increase life span. This gene codes for a protein that converts Q8 ubiquinone, supplied by bacteria, to Q9 and other ubiquinone species, used in oxidative phosphorylation [34]. Although it is not precisely yet clear how mutations in the $c l k-1$ gene increase life span, the increased life span does not appear to be due to reduced respiration $[35,36]$ or increased superoxide dismutase (SOD) or catalase [36]. However, it has now been demonstrated that the $c l k-1$ mutation depresses complex I activity while sparing complex II activity [37], thus favoring the utilization of complex II at the expense of complex I. Similarly, in mice, ablation of the p66shc gene increases life span and reduces the production of reactive oxygen species, apparently by reducing NADH levels and thus the utilization of complex I [38]. Interestingly, a mutation in NADH dehydrogenase, a key enzyme in complex I, is also associated with increased longevity in humans [39].

\section{Dietary Restriction May Increase Life Span by Reducing Oxidative Stress through a clk-1-Like Mechanism}

Dietary restriction may increase life span through a clk-1-like mechanism, since effects of dietary restriction and the clk-1 mutants on life span are reported to be nonadditive [40]. This hypothetical common mechanism does not appear to require a reduction in metabolic rate, since neither the $c l k-1$ mutation $[35,36]$ nor dietary restriction $[41,42]$ reduce mass-specific oxygen 
consumption in C. elegans. Similarly, the mechanism by which dietary restriction increases life span in yeast [3] and mammals [1,43] appears not to require a reduction in mass-specific oxygen consumption. On the other hand, several lines of evidence suggest that a final common mechanism by which life-extending mutations $[44,45]$ and dietary restriction $[46,47]$ increase life span entails reducing oxidative damage. Furthermore, dietary restriction reduces the activity of complexes I, III and IV [48]; ATP production is presumably maintained by elevation of the relative complex II function. Similarly, dietary restriction decreases the production of reactive oxygen species in complex I without reducing mitochondrial oxygen consumption or reducing the production of reactive oxygen species in complex II [49-51]. The authors of these elegant studies concluded that 'caloric restricted mitochondria released less reactive oxygen species per unit electron flow, due to a decrease in the reduction degree of the complex I generator' [50]. Since mitochondrial oxygen consumption did not change, this mechanism likely involves an increase in the relative utilization of complex II. These data suggest that dietary restriction, possibly like the $c l k-1$ mutation, may increase life span by causing a relative reduction in the utilization of complex I and a relative enhancement in the utilization of complex II, without necessarily reducing the overall metabolic rate.

\section{Dietary Restriction Reduces Glycolysis and Increases Oxidation of Lipids and Amino Acids; Aging Produces the Opposite Profile}

The mechanism by which dietary restriction might produce this relative shift toward the utilization of complex II is suggested by studies examining effects of dietary restriction on the expression of metabolic genes and levels of metabolic products. Dietary restriction in most tissues produces a metabolic profile indicating a striking shift away from glycolysis and toward lipid metabolism, whereas aging produces the opposite profile relative to the young ad libitum profile [2]. The metabolic shift away from glycolysis in dietary restriction is illustrated by the effect of dietary restriction to increase PDK-4 [52]. PDK-4 is a key inhibitor of pyruvate dehydrogenase, which controls the rate-limiting step in the recruitment of glucose-derived carbons for complete oxidation in the Krebs cycle [53]. Conversely, the metabolic shift toward lipid metabolism is illustrated by the effect of dietary restriction to increase expression of carnitine palmitoyl transferase 1, the rate-limiting enzyme for the transfer of lipids to the mitochondria [2, 54]. Similarly, direct analysis of glycolytic enzyme activities and metabolic products in young and old liver from ad libitum fed and dietaryrestricted mice elegantly demonstrated the same phenomenon, that chronic 
dietary restriction strikingly reduces glycolysis while apparently increasing reliance on lipid (and possibly amino acid) mitochondrial oxidation [55]. While reducing glycolysis, dietary restriction apparently increases the metabolism of glucose through the alternative pentose pathway, as evidenced by the induction of transketolase [2]. Thus dietary restriction produces a shift away from glucose metabolism in glycolysis, but increased metabolism in the pentose pathway, and toward lipid and amino acid oxidation, whereas aging produces the opposite effect. The significance of this metabolic profile for the regulation of life span is suggested by the observation that antioxidants produced many of the same effects as did dietary restriction, but failed to prevent the age-related shift toward glycolysis and also failed to increase life span [56]. As indicated above and as also described below, the effect of dietary restriction on metabolic gene expression is highly similar to the effect of hypoglycemia, i.e. the opposite of the effect of elevated glucose. This similarity further supports that in mammals effects of dietary restriction on life span are mediated by a reduction in exposure to glucose [1], as is the case in yeast [3].

It should be noted of course that dietary restriction also reduces insulin secretion, and genetic ablation of insulin-like pathways increases life span in worms [57] (see Houthoofd et al. in this volume), mice [58] (see Bartke et al. in this volume) and flies [59] (see chapter by Tatar in this volume). Furthermore, insulin produces metabolic effects (e.g. increased glycolysis and reduced $\beta$-oxidation) that are similar to, and thus potentially similarly as toxic as, those produced by glucose. These observations initially suggested that dietary restriction might increase life span by reducing insulin secretion. However, subsequently it has been shown that dietary restriction and ablation of the insulin-like pathway produce additive effects in worms [60] and mice [61], leading many investigators to conclude that dietary restriction increases life span through a mechanism other than reducing insulin secretion. This conclusion was questioned by elegant studies in flies [62], but as discussed in the chapter by Tatar in this volume, even those studies are not definitive. On the other hand, it should be noted that not all tissues are equally insulin sensitive, and in fact about half of the glucose disposal under normal conditions is not regulated by insulin. Therefore we hypothesize that aging is driven by the proglycolytic gene profile produced by both insulin and glucose, but that dietary restriction increases life span only by reducing glucose exposure because the reduction in insulin secretion is balanced by increased insulin sensitivity. Thus dietary restriction is additive with ablation of the insulin-like pathway because further reduction of glycolysis in insulin-sensitive tissues is additive with the reduction in glycolysis produced by dietary restriction. In short, we propose that the glucose switch with hysteresis is a final common pathway between dietary restriction and the insulin-like pathways. 
Because diabetes accelerates many age-related pathologies, especially cardiovascular diseases, hyperglycemia has long been considered a model for aging, thus leading to the hypothesis that exposure to glucose drives the aging process $[63,64]$. Among many commonalities between diabetes and aging is that both conditions entail mitochondrial impairments that probably drive many of the pathologies associated with those conditions $[65,66]$. An interesting model of aging has been developed in which mitochondrial function is impaired by genetic deletion of a mitochondrial transcription factor in specific tissues [67]. This model is characterized by progressive failure of function and progressive reduction in ATP synthesis in a variety of tissues, and, as has been suggested for aging, the reduced metabolic capacity was initially thought to be the cause of the progressive pathology. However, detailed examination of gene expression demonstrated that before significant pathology developed, genes that stimulated glycolysis were induced and genes that stimulated $\beta$-oxidation were inhibited [67]. The authors concluded that 'at least some of the secondary gene expression alterations in mitochondrial cardiomyopathy do not compensate but rather directly contribute to heart failure progression' [67]. In view of the evidence discussed above, it is clear why this profile of gene expression would produce pathologies and supports the hypothesis that the impairments in mitochondrial function observed during aging in many studies and tissues [66] could be secondary to the switch in metabolism toward enhanced glycolysis and reduction in $\beta$-oxidation.

\section{Glucose Oxidation Favors Complex I, Lipid/Amino Acid Oxidation Favors Complex II}

The significance of the shift in source of carbon atoms for oxidation produced by dietary restriction may be that the oxidation of lipids and amino acids depends much more on mitochondrial complex II than on (free-radical generating) complex I, whereas glucose oxidation depends much more on complex I than on complex II. When glucose is broken down by glycolysis, the only reducing equivalents it makes are in the form of NADH. When the final carbon product of glucose, pyruvate, is metabolized in the Krebs cycle, almost all the reducing equivalents are produced in the form of NADH, except for one step at complex II (succinate dehydrogenase) that makes (then oxidizes) FADH2. Ultimately the metabolism of one molecule of glucose produces an NADH: FADH2 ratio of 5:1 [53, p. 20]. In contrast, when lipids are broken down by $\beta$-oxidation (fatty acid counterpart to glycolysis), an equal number of NADH and FADH2 molecules are formed. When the lipid-derived carbons are metabolized in the Krebs cycle, reducing equivalents are produced in the ratio of 
3 NADH molecules per FADH2 molecule. Therefore ultimately lipid metabolism yields an NADH:FADH2 ratio of about 2:1 [53, p. 38] or even less if the fatty acid contains enough carbon atoms. For example, when one molecule of palmitate is oxidized, it produces 15 molecules of FADH2 and 31 molecules of $\mathrm{NADH}$, which are ultimately oxidized to produce a net total of 129 ATP molecules. In contrast, production of the same number of ATP molecules from glucose would entail producing then oxidizing 8.66 FADH2 and 43.3 NADH molecules. Amino acid oxidation also proceeds by a similar 2-step mechanism yielding an NADH:FADH2 ratio between that of lipids and that of glucose, the precise number depending on the specific amino acid. The significance of this shift in the NADH:FADH2 ratio is that NADH is oxidized only at mitochondrial complex I, whereas FADH2 is oxidized only at complex II [53, p. 17]. Thus palmitate oxidation entails utilizing complex II at roughly twice the (FADH2dependent) rate as glucose oxidation entails. Therefore shifting away from glucose utilization toward lipid and amino acid utilization would be expected to substantially reduce the production of reactive oxygen species, without necessarily reducing ATP production. As described below, other beneficial effects also occur as a result of this altered pattern of glucose fuel use, including a shift toward producing antioxidizing NADPH and increased protein and lipid turnover, which reduces the accumulation of oxidized protein and lipids.

\section{Potential Cumulative Toxic Effect of Glucose on Neuroendocrine Neurons Regulating Metabolic Function}

A guiding hypothesis for our research program for almost 20 years has been that longevity is governed in part by a cumulative toxic effect of glucose, particularly on glucose-sensitive neuroendocrine cells in the hypothalamus and pancreas, a phenomenon we referred to as glucose hysteresis [13, 14]. Similarly Masoro et al. [1] proposed the hypothesis that 'dietary restriction retards the aging processes by altering the characteristics of (glucose) fuel use'. Our 'glucose hysteresis' hypothesis and Masoro's 'glucose fuel use' hypothesis are potentially complementary and could represent two aspects of the same overall mechanism, but exactly how these mechanisms are related has been unclear until recently (see below).

Our hypothesis suggested that key peptides expressed in glucose-stimulated hypothalamic neurons would: (1) be reduced during aging; (2) be reduced by fasting and in genetic obesity; (3) be reduced by treatment with the glucose toxin gold thioglucose; (4) be stimulated by glucose and other nutritional factors; (5) exert catabolic neuroendocrine effects, and impairment in the function of such peptides would exert anabolic effects; (6) be irreversibly impaired by 
prolonged exposure to elevated glucose. In a series of studies we have found that hypothalamic $\alpha$-melanocyte-stimulating hormone, which is produced from the proopiomelanocortin (POMC) precursor and is preferentially reduced during aging [68-73], is reduced by fasting and in genetic obesity [74], and is reduced by gold thioglucose [75]. POMC neurons are stimulated by glucose and other nutritional factors [76], and transgenic correction of reduced hypothalamic POMC corrects impairments in glucose homeostasis in obese mice [77]. Thus age-related impairments in hypothalamic POMC could plausibly contribute to age-related obesity and metabolic impairments. However, although we hypothesized that cumulative toxic effects of glucose cause the age-related reduction in hypothalamic POMC, the mechanism by which glucose would cause such a toxic effect has until recently been elusive.

\section{Glucose Metabolism Is Necessary for Effects of Glucose on Glucose-Regulated Neurons: Key Role for the Production of NADH}

To further assess the hypothesis that cumulative exposure to glucose may drive hypothalamic impairments during aging, it was necessary to assess in more detail the mechanisms by which these neurons sense glucose. Such studies have been useful for two reasons. First, determination of key elements of the glucose-sensing apparatus has provided useful markers to test the generality that glucose-sensitive neurons are specifically sensitive to aging and to protective effects of dietary restriction. Second, assessment of the sensing mechanisms suggested mechanisms, described below, mediating the vulnerability of such neurons to glucose toxicity.

Our working hypothesis was that hypothalamic neurons sense glucose through a mechanism similar to that utilized by pancreatic $\beta$-cells. It is well established that the pancreatic form of the enzyme glucokinase constitutes a key component of the glucose-sensing mechanism in pancreatic $\beta$-cells [78-82]. We observed that the pancreatic form of glucokinase is expressed in hypothalamic neurons, but not significantly in the rest of the brain [83], consistent with results by Jetton et al. [84] and corroborated in detail by Lynch et al. [85]. Based on these results, we examined in greater detail the extent to which hypothalamic neurons sense glucose through mechanisms similar to those of pancreatic $\beta$-cells.

Extensive examination with both metabolic inhibitors and glycolytic intermediates demonstrated that, like pancreatic $\beta$-cells, hypothalamic neurons sense glucose through glucose metabolism [83]. In particular, inhibitors of glucokinase blocked the response of hypothalamic neurons. However, surprisingly a key step was the conversion of NAD + to NADH and not, as expected, the 
production of ATP [83]. The significance of this observation became clear when it was found that the NADH shuttle system plays a key role in mediating effects of pancreatic $\beta$-cells to glucose [86]. Of even greater potential significance, these studies suggest that glucose metabolism may drive specific neuroendocrine age-related impairments, through the conversion of $\mathrm{NAD}+$ to $\mathrm{NADH}$, a mechanism similar to that reported in yeast [87].

\section{Glucose Regulates Its Own Metabolic Fate: The Glucose Switch Gene Profile}

As indicated above, several lines of evidence suggested that protective effects of dietary restriction could be mediated by reduction of glucose [13] leading to changes in glucose utilization [1] through 'metabolic reprogramming' [2], but the mechanism mediating these effects has remained unclear. To address this question we sought to discover genes regulated by glucose using DNA microarray analysis. In our studies of the regulation of POMC by leptin, we had found that gene regulation often occurs more robustly to ablation of a signal than to enhancement of a signal [74]. Therefore to discover genes regulated by glucose, we examined molecular responses to low glucose (hypoglycemia) compared to normal glucose (euglycemia) [88]. We examined responses in the hypothalamus since we hypothesized that neuroendocrine responses to glucose would be particularly important in mediating effects of glucose on life span [13]. Hypoglycemia was produced by injecting mice that had been food deprived for $48 \mathrm{~h}$ with insulin; therefore initially we could not determine if the regulation was due to fasting or hypoglycemia; however, we subsequently demonstrated with RT-PCR that almost all genes regulated by fasting alone were also regulated similarly by hypoglycemia alone [88].

In our initial study, using a small cDNA microarray of our own fabrication, we observed only a fairly small number of genes induced in association with hypoglycemia [88]. Among these genes were the glucose transporter GLUT-1, and the transcription factor CITED-1, also known as p300/CBP-interacting protein. The induction of GLUT-1 by hypoglycemia suggested that reduced glucose would produce a compensatory increase in glucose utilization, which would limit the importance of this mechanism in mediating effects of dietary restriction. However, it seemed unlikely that this analysis provided a comprehensive view of the molecular effects of glucose, since only about 1,000 genes were represented on this cDNA microarray. We therefore used the much more extensive U74 microarray chip to analyze the same RNA samples as were analyzed in the cDNA microarray study. Focusing specifically on genes coding for intermediary metabolism function (representing several hundred genes), only 26 met 
criteria that we had established as highly predictive of true regulation verifiable by RT-PCR [89].

Examination of this select group of genes provided a strikingly clear mechanism activated by hypoglycemia, a mechanism we call the 'glucose switch'. Specifically, hypoglycemia was associated with reduced expression of genes that stimulate glycolysis (e.g. phosphofructokinase) and mitochondrial utilization of carbons derived from glucose (e.g. by inducing PDK-4, which inhibits pyruvate dehydrogenase). Nevertheless, this study confirmed that GLUT-1 was induced by hypoglycemia, implying that glucose carbons were being utilized in nonglycolytic pathways. Several genes whose products stimulate the pentose pathway were also induced, suggesting that hypoglycemia leads to a shunting of glucose carbons away from glycolysis towards the pentose pathway. In contrast, genes coding for peroxisomal proteins and genes involved in protein degradation and utilization of amino acids were induced by hypoglycemia. Furthermore, a rate-limiting enzyme for the tricarboxylic acid cycle, NADP-dependent isocitrate dehydrogenase, was also induced by hypoglycemia, suggesting that overall respiration might actually be increased, not decreased, by hypoglycemia. It should be noted that, as indicated above, this general metabolic profile, away from glycolysis and toward the pentose pathway, $\beta$-oxidation and protein turnover is very similar to that produced by chronic dietary restriction $[2,54$, $55,90]$.

This profile of gene expression implies a strikingly clear response to low glucose that could serve as the mechanistic basis of Masoro's 'alternate fuel use' and the 'reprogramming' hypothesis (see Anderson and Weindruch in this volume) to explain effects of dietary restriction on life span. This response to low glucose involves extensive rerouting of glucose and other carbons without reducing (indeed, possibly elevating) the respiration rate. Hence we refer to this response as the 'glucose switch' profile. In this response to low glucose, glucose carbon atoms are shunted away from production of NADH through glycolysis and toward synthesis of NADPH through the pentose pathway and by the NADP-dependent form of isocitrate dehydrogenase. Since NADPH is the only major source of reducing equivalents for antioxidant defense, this profile would be expected to enhance antioxidant defenses. For example, elevation of glucose-6-phosphate dehydrogenase, the rate-limiting step in the pentose pathway, produces dramatic resistance to oxidative damage without changing levels of catalase or SOD [91, 92], whereas reduction of this enzyme greatly enhances cellular sensitivity to oxidative stress [93]. The pentose pathway absolutely requires carbons derived from glucose, so for this essential source of cytoplasmic NADPH to function in the presence of low glucose, alternative metabolic pathways for glucose carbons must be inhibited by low glucose, which they robustly are at several rate-limiting steps. Indeed, polymorphisms in the gene 
for glucose-6-phosphate dehydrogenase are strikingly correlated with life span across strains of Drosophila: the longest-lived strain exhibited a $64 \%$ higher activity of glucose-6-phosphate dehydrogenase than the shortest-lived strain [94]. Similarly, the NADP-dependent form of isocitrate dehydrogenase is a major source of NADPH in mitochondria, and elevation of this enzyme protects against oxidative stress in vitro [95] and even increases replicative life span [95]. Furthermore, expression of this enzyme decreases with age [96] and variants in NADP-dependent isocitrate dehydrogenase were associated with life span in Drosophila [97].

Interestingly, however, this 'alternate pattern of fuel use' produces two other possibly coincidental antioxidative effects. First, as indicated above, $\beta$ oxidation of lipids, the lipid equivalent of glycolysis to prepare lipid carbons of oxidative phosphorylation in the Krebs cycle, produces reducing equivalents in the form of FADH2, rather than the NADH produced by glycolysis. FADH2 is oxidized at mitochondrial complex II, whereas NADH is oxidized at mitochondrial complex I. As reviewed above, reactive oxygen species are produced at much greater rates in complex I than in complex II, and indeed mutations in complex I extend life span whereas mutations in complex II reduce life span. Therefore a shift toward lipid oxidation (and to a lesser extent amino acid oxidation) would be expected to produce a lower rate of reactive oxygen species compared to deriving energy from glucose. Second, by enhancing the turnover rate of proteins and lipids, the average half-life of these macromolecules will be reduced, thus reducing the cellular burden of oxidatively damaged macromolecules. A final effect of this 'alternate fuel use' would be to dramatically shift the redox state of the NAD system away from NADH toward NAD+, though the overall redox state of the cell would be shifted toward a reduced state by elevation of NADPH and FADH2. It has been reported that the effect of dietary restriction to increase life span (in yeast) requires the activity of the silencing protein SIR2 which is dependent on (oxidized) NAD+ [87]. Although the precise role of NAD + in regulating SIR2 activity has been disputed, considerable evidence supports that the NAD+:NADH ratio serves as a key signal for the metabolic state of the cell, as we showed in our own studies [83]. The significance of this shift has therefore to be fully elucidated.

It should be noted that this antioxidant profile is potentially independent of the classic antioxidant system involving SOD and catalase, although we did find that hypoglycemia induced several isoforms of SOD, glutathione peroxidase and glutathione reductase (though not catalase), consistent with effects of dietary restriction $[98,99]$. In fact, we have found that hypoglycemia decreases, and hyperglycemia increases, expression of other isoforms of SOD and that ablation of specific isoforms of SOD has no effect on life span in C. elegans [Yen et al., unpubl. data], consistent with studies in mice [100]. Furthermore, 
expression levels of SOD either did not correlate with life span or even correlated negatively with life span across 5 strains of mice (see below). On the other hand, even to the extent that classic antioxidant defenses play a role in the aging process, it should be noted that glutathione, a key metabolite in antioxidant defenses, ultimately derives its reducing potential from NADPH and thus mainly from glucose-6-phosphate dehydrogenase and NADP-dependent isocitrate dehydrogenase.

Based on these observations, we propose that glucose regulates its own metabolic fate, promoting glycolysis and reducing the relative activity of the pentose pathway, $\beta$-oxidation and amino acid oxidation. Thus glucose produces a metabolic profile that produces NADH at the expense of NADPH and FADH2. The net effect of elevated glucose would therefore be to decrease antioxidant capacity (by decreasing NADPH), decrease the activity of Sir-type histone acetyltransferases (by converting NAD + to NADH), increase the production of free radicals (by promoting the oxidation of NADH at complex I, which is the main site of free radical production, at the expense FADH2 oxidation at complex II, which is a minor site of free radical generation) and decrease the turnover of oxidized lipids and proteins (by decreasing $\beta$ - and amino acid oxidation).

While the 'glucose switch' hypothesis clearly suggests a mechanism for diabetic complications, which are currently thought to be due to oxidative damage [101], by itself it would be insufficient to explain the aging process, since glucose levels in general do not increase with age. Even for diabetic complications, however, the glucose switch mechanism by itself does not explain why, as with aging, impairments develop progressively and are apparently irreversible. To explain the progressive nature of aging and diabetic complications, we propose that the glucose switch transcriptional machinery exhibits hysteresis, as demonstrated with the highly analogous lac operon [19]. As described above, the lac operon exhibits hysteresis, in that sensitivity to the inducer depends on the history of exposure: if previously exposed to a high concentration of inducer, the operon is highly sensitive to inducer, whereas if previously exposed to a low concentration of inducer, the operon is relatively insensitive to inducer. Also as described above, there is evidence that the regulation of gene expression by glucose also exhibits hysteresis [21,22]. Indeed, to the extent that transcriptional effects of glucose are mediated through NADH, the glucose switch mechanism directly predicts glucose hysteresis: since glucose induces the machinery to produce NADH, prior exposure to elevated glucose would subsequently lead to more NADH production per glucose molecule, i.e. greater sensitivity to glucose.

Thus two features of the lac operon lead to a comprehensive mechanism that accounts for key features of aging, dietary restriction and diabetic complications: that substrates induce the machinery of their own metabolism (in the 
case of glucose especially, at the expense of alternative pathways), and that this self-induction entails hysteresis. Therefore we propose that postprandial excursions of glucose produce a glucose switch response, inducing glycolysis at the expense of $\beta$-oxidation, a state that would tend to persist even when glucose levels return to their preprandial levels. It should be noted that hysteresis in the lac operon is observed stochastically across cells so that the lac operon is either completely on or completely off. Thus we propose that the effect of successive exposures to (postprandial) glucose would be to produce progressively more cells in the proglycolytic glucose switch position. It should be noted, however, that as glycolysis increases and produces monotonic increases in oxidative damage, especially in mitochondria, and a greater reliance on glycolysis, this could eventually lead to a reduction in mitochondrial metabolic capacity in the late phases of senescence, which could be a final precipitating event leading to mortality, as appears to be the case with mitochondrial impairments produced by genetic modification [67]. The elevation of insulin secretion early during the prediabetic phase of type 2 diabetes, followed by a reduction in insulin secretion as the precipitating event of diabetes itself, might be considered an analogous process, and indeed may well be produced by exactly the same mechanism (increased glycolysis leading to increased secretion, followed by oxidativestress-induced 'burnout', followed by hyposecretion of insulin and diabetes).

\section{Genetic Correlation between Gene Expression and Life Span}

Other than two studies linking life span to expression levels of glucose-6phosphate dehydrogenase [94] or to variants in NADP-dependent isocitrate dehydrogenase [97], very few studies have directly linked variations in levels of glucose-sensitive genes to life span. We therefore examined the correlation between hypothalamic expression of glucose-sensitive genes and average life span across 5 strains of mice. This analysis was validated by the observation that, in our analysis, hypothalamic expression of sirtuin 2, the mammalian homolog of yeast SIR2, was positively correlated with life span $\left(\mathrm{r}^{2}=74 \%\right)$ and inhibited by 10 versus $2 \mathrm{~mm}$ glucose $(\mathrm{p}<0.01)$ as well as leptin, thus behaving quite similarly to yeast Sirt-2 [87]. Over $90 \%$ of the genes whose expression correlated positively with life span (and with an $\mathrm{r}^{2}$ greater than $70 \%$ ) were inhibited by glucose in vitro. Most of these genes were transcription factors or involved in neuroendocrine signaling. For example, expression of polycomb group ring finger 5 correlated positively with life span $\left(\mathrm{r}^{2}=75 \%\right)$ and was significantly and independently inhibited by glucose, leptin and insulin $(\mathrm{p}<0.05$ for all three). Interestingly, polycomb transcription factors primarily function to inhibit gene 
expression [102], as is the case for genes in the sirtuin family. Conversely, genes that correlated negatively with life pan were generally induced by glucose. For example, the transcription factor hypoxia-induced factor $1 \alpha$ is negatively correlated with life span $\left(r^{2}=83 \%\right)$ and induced by glucose $(\mathrm{p}<0.01)$. The significance of the relationship between hypoxia-induced factor $1 \alpha$ and life span may be that this gene is an important stimulator of glycolysis [103]. Indeed, pyruvate dehydrogenase expression is negatively correlated with life span and stimulated by glucose. Also of some interest in view of the hypothesis of Andersen and Weindruch (in this volume), the expression of the peroxisome proliferationactivated receptor $\gamma$ coactivator $1 \alpha$ is also highly and positively correlated with life span $\left(\mathrm{r}^{2}=83 \%\right)$. Similarly, hypothalamic expression of the gene for stearoyl coenzyme A desaturase 1 is positively correlated with life span $\left(\mathrm{r}^{2}=83 \%\right)$. The significance of these latter two genes is that they are induced by free fatty acids (which of course are elevated during fasting and dietary restriction for prolonged periods of time) and act primarily to increase fat metabolism. Thus across 5 strains of mice, elevated expression of glucose-stimulated genes predicts a reduced life span and elevated expression of glucose-inhibited genes predicts an increased life span; expression of genes induced by free fatty acids also predicts a longer life span.

\section{Problems}

The glucose hysteresis hypothesis suggests, though does not require, that the respiratory quotient (RQ) should increase with age, reflecting more carbohydrate utilization and less $\beta$-oxidation, whereas dietary restriction should produce the opposite effect. While some studies have reported an increase in RQ with age [104], others have not observed this effect. Similarly, while one study reported that dietary restriction reduces 24-hour RQ [43] (though not specifically indicating the significance of this effect), in a different study, although the same effect of dietary restriction to reduce RQ was observed, the effect was not significant [1]. In our own studies (unpublished) we observed that chronic dietary restriction in young mice significantly reduced 24-hour RQ by about the same amount as reported by McCarter et al. [43] in rats. Although the effect was small, it was about the same magnitude as observed for the effect of a highfat diet. We therefore conclude that while measurements of RQ are not uniformly supportive of the glucose switch hypothesis, neither are they uniformly contradictory. Further studies should clarify this issue. Nevertheless, even if the reduction of total 24-hour RQ by dietary restriction is not robust, we would suggest that the robust alteration in temporal pattern, in which lipid is the dominant fuel for a much longer part of the day with dietary restriction than with ad 
libitum food intake, would still produce a protective effect by reducing the total time glucose metabolism is the main source of energy.

The glucose hysteresis hypothesis also predicts that glycolysis relative to alternate sources of fuel should increase with age, which is observed in the heart [2], brain [54], and liver [55], but in mouse muscle at least some genes for glycolysis as well as many other genes coding for mitochondrial function were reported to decrease with age [105]. On the other hand, this decrease in glycolytic gene expression was not observed in muscle tissue from nonhuman primates [52]. Therefore we hypothesize that even though expression of some glycolytic genes may decrease with age in mouse muscle, the utilization of other fuels (e.g. $\beta$-oxidation) decreases more so that the net effect is still a shift toward glycolysis. Similarly, the hypothesis predicts that dietary restriction should decrease glycolysis relative to the use of other fuels, which is observed in yeast [5], flies [106], the heart [2], liver [55] and brain [54], but in adipose tissue, long-term dietary restriction was reported to increase the expression of glycolytic genes [107]. However, dietary restriction also robustly increased many other metabolic pathways in adipose tissue, including $\beta$-oxidation and the synthesis of fatty acids. As with mouse muscle in aging, therefore, it is difficult to determine simply from gene expression whether glycolysis is actually increased or decreased relative to other metabolic pathways.

A possibly more serious problem with the emphasis on glucose metabolism is that restriction of methionine only is reported to increase life span in rats [108] and mice [109]. Furthermore, restriction of yeast is reported to extend life span in flies more robustly than restriction of glucose [110]. On the other hand, dietary restriction without reduction in protein extends life span as well as dietary restriction with reduction of protein [111]. Furthermore, reduction of lipids only without reduction of caloric intake failed to increase life span [112]. Therefore while the effect of (extreme) methionine restriction is indeed interesting, it is unlikely to mediate the effects of dietary restriction on life span, at least in rats. With regard to the methionine effect in mice, it is of some interest that methionine restriction reduced plasma glucose, raising the possibility that restriction of methionine actually increases life span by reducing blood glucose, as we propose for dietary restriction [109]. Regarding the role of glucose versus yeast in flies, there are a number of complexities in the design of that study which precludes definitive interpretation, as described by Tatar in the present volume. Perhaps the best position to take at the moment is that across species it is not clear how much of the effect of dietary restriction is due to reduced exposure to glucose. To the extent that the effect is due to reduction in exposure to glucose, we propose that glucose hysteresis is a mechanism that could explain these toxic effects of glucose during aging. We further propose that at least with respect to one major disease of aging, diabetes, glucose hysteresis constitutes 
the major mechanism mediating the effects of hyperglycemia to induce diabetic complications.

\section{Implications: Oxidative Stress and Tumor Burden}

As described above, glucose hysteresis is a relatively simple unitary mechanism that potentially explains the following apparently otherwise unrelated phenomena: (i) glycolysis increases with age (in at least some tissues); (ii) oxidative damage increases with age; (iii) reducing glycolysis or the activity of ETC complexes I, III, IV and V increases life span, whereas reducing the activity of ETC complex II reduces life span; (iv) dietary restriction increases the relative utilization of complex II; (v) intermittent dietary restriction that does not reduce the average caloric intake nevertheless produces beneficial effects of dietary restriction, associated with reduced plasma glucose [113]. Thus glucose hysteresis can plausibly account for the majority of age-related impairments arising from oxidative stress and their attenuation by dietary restriction.

However, the attenuation by dietary restriction of at least one major agerelated pathology probably does not arise by decreasing oxidative stress: tumor burden. As described by Klebanov in this volume, dietary restriction primarily if not exclusively reduces tumor burden by inhibiting the promotion phase of tumor growth. However, it is difficult to envision a mechanism by which reducing oxidative damage would inhibit the promotion phase. If anything, it would be the initiation phase that would probably be sensitive to oxidative stress. These considerations would seem to suggest that dietary restriction reduces oxidative stress and tumor burden by two distinct mechanisms and, conversely, that aging promotes these two pathological processes through distinct mechanisms. Nevertheless, the glucose switch hypothesis suggests a unifying mechanism: increased glycolysis during aging. Tumor cells are characterized by a unique dependency on glycolysis, a phenomenon known as the Warburg effect [114, 115]. This unique dependency on glycolysis possibly arises from mitochondrial damage, but has the effect of allowing tumor cells to thrive at relatively low oxygen tensions typically observed in tumors. Of particular interest, this unique dependency on glycolysis makes tumor cells highly sensitive to the toxic effects of glycolysis inhibitors, which have therefore been proposed as a promising class of antitumor agents [116]. It is therefore plausible that tumor cells are particularly sensitive to the low levels of glucose, and the resulting shift away from glycolysis, that are at least transiently produced by dietary restriction. Indeed, even a transient (3-hour) reduction in ATP produces robust apoptosis in transformed cells, $48 \mathrm{~h}$ later [117]. Furthermore, glycolytic inhibitors have been shown to produce many of the protective effects of dietary restriction [118]. Thus 
reduction in glycolysis reduces both oxidative stress and tumor burden, thereby potentially accounting for most or all beneficial effects of dietary restriction.

A final implication of glucose hysteresis is its relevance to the genetic control of longevity. A key aspect of the theory is that it is largely independent of the classic antioxidant enzymes catalase and SOD, and focuses instead on the production of reactive oxygen species in complex I, as well as the role of increased protein and lipid turnover. However, it is by now well established that across species, 'the longer the life span, the lower the rate of mitochondrial oxygen radical production. This is true even in animal groups that do not conform to the rate of living theory of aging, such as birds' [119-121]. Similarly, as described above, genes involved in the glucose switch mechanism constitute the main set of genes that limit life span, according to nonbiased genome-wide screening [26]. In contrast, activities of the classic antioxidant defense enzymes do not correlate with life span across species [122]. Furthermore, it is now clear that impairments in classic antioxidant defenses do not reduce life span, even when such impairments increase oxidative damage [100]. Thus we propose that genetic influences on the regulation of gene expression by glucose could constitute key genetic influences that regulate life span. On the other hand, there are at least two relevant potentially distinct genetic influences, those that influence acute control of gene expression by glucose and those that influence the development of hysteretic effects. We suggest that genetic effects on both of these mechanisms must play a role in determining life span, since even at a young age species differ in their rate of production of reactive oxygen species [119] (possibly reflecting at least in part the acute effects of glucose on complex I activity), but on the other hand, the age-related increase in oxidative damage, reflecting hysteresis, scales with life span [123-125]. Thus we suggest that the rate of hysteresis may also be higher in short-lived than in long-lived species [119].

\section{Context}

It is of some interest to place the mechanism of glucose hysteresis into the context of current approaches being developed in the field of dietary restriction, as reflected in the present volume. First, Masoro has elegantly developed the concept that dietary restriction acts through hormesis, a protective mechanism activated by low-level stressors. Our proposal is quite consistent with this hypothesis, since hypoglycemia is a classic inducer of the stress response. Thus, for example, reduction of blood glucose stimulates secretion of glucocorticoids (a classic stress response) in mice [126], rats [127] and humans [128]. Similarly, reduction of blood glucose activates the sympathetic nervous system, also a classic stress response, in mice [129], rats [127] and humans [128]. Indeed, 
hypoglycemia even produces homotypic densitization, a classic feature of stress responses, in mice [129], rats [127] and humans [130].

Anderson and Weindruch in the present volume extend the concept, already articulated by Weindruch and colleagues previously [2], that protective effects of dietary restriction may be mediated through 'transcriptional reprogramming'. Clearly glucose hysteresis represents precisely an example of transcriptional reprogramming, and indeed the work of Weindruch and colleagues represents some of the most important evidence for the mechanism. Bartke et al. in the present volume examine the allied concept that effects of the insulin-like pathway and dietary restriction are mediated by a common set of genes. While so far the evidence does not support this hypothesis, as argued above, it may well be the case that the proglycolytic effects of insulin drive senescence in insulin-sensitive tissues, whereas the proglycolytic effects of glucose drive senescence in insulininsensitive tissues.

Morgan et al. in the present volume develop an elegant argument that many age-related pathologies arise from age-related increases in inflammatory processes and that dietary restriction attenuates age-related impairments in part by reducing inflammation. Morgan et al. also speculate about mechanisms mediating effects of dietary restriction to reduce inflammation, including a role for glucose acting through the receptor for advanced glycation end products. However, while this is a plausible explanation for the effect of dietary restriction, this mechanism fails to explain why inflammation increases with age, since in general, certainly in rodents, plasma glucose does not increase with age. Furthermore, elevated glucose induces cytokines very rapidly (within a few hours) through a mechanism requiring glucose metabolism [131], whereas advanced glycation end products develop far too slowly to account for such rapid effects. However, as emphasized by Morgan et al., at least some cytokines are induced by reactive oxygen species. We therefore suggest that inflammation increases with age because of increased reactive oxygen species, secondary to glucose hysteresis, and that dietary restriction retards this age-related increase in inflammation by reducing exposure to glucose.

Houthoofd et al. in the present volume describe the value of $C$. elegans as a model organism. We completely agree that $C$. elegans constitutes possibly the most powerful system to study mechanisms of aging, and indeed much of the most compelling support for the mechanism of glucose hysteresis comes from studies in C. elegans. Houthoofd et al. also argue strongly against the rate of living theory and indicate that dietary restriction increases life span without reducing metabolic rate, a conclusion also drawn by investigators studying rodents $[1,43]$. In our view one of the most compelling aspects of the glucose hysteresis model is that, by invoking substrate competition, it can explain how the oxidative damage can decrease even without reducing ATP production. 
Interestingly, Tatar in the present volume reviews the use of Drosophila in aging research and carefully analyzes difficulties in interpreting studies that suggest a minimal role for glucose mediating the effects of dietary restriction [110]. As discussed in some detail elsewhere [132], a number of results suggest that mechanisms mediating effects of dietary restriction in Drosophila, and indeed mechanisms of senescence themselves, may be distinct to some extent from those in other species. It should be noted that of the many organisms and experimental paradigms described in the present review in support of the glucose hysteresis hypothesis, none have involved Drosophila. This corroborates the importance of studying these mechanisms in a wide variety of organisms to probe for the generality of those mechanisms. On the other hand, as described by Mattison et al. in the present volume, so far dietary restriction appears to produce similar results in nonhuman primates, including a reduction in mean blood glucose. We take this as evidence that dietary restriction is therefore likely to actually increase life span in nonhuman primates.

In the final two chapters of the present volume, effects of dietary restriction on specific disease processes, Alzheimer's disease and cancer, are discussed. We should note that we have no plausible mechanism through which the specific effects of dietary restriction on $\beta$-amyloid peptide generation described by Pasinetti et al. in the present volume can be accounted for by glucose hysteresis, and agree with them that insulin, rather than glucose, probably plays a key role. On the other hand, in view of the critical role of oxidative stress in mediating $\beta$-amyloid peptide toxicity in particular [133] and neurodegeneration in Alzheimer's disease in general [134], it is plausible that glucose hysteresis plays a role in the age-related neurodegeneration associated with Alzheimer's disease. Finally, in the last chapter Klebanov makes a strong case that dietary restriction reduces cancer burden specifically by interfering with the promotion phase of tumor growth, not the initiation phase. As noted above, the promotion phase is unlikely to be dependent on oxidative stress, in contrast to the initiation phase. However, also as indicated above, tumor cells become increasingly dependent on glycolysis as they progress, due to the Warburg effect [114]. Therefore, the effect of dietary restriction to interfere with the promotion phase is plausibly due directly to the reduction of glycolytic capacity, rather than the reduction of oxidative stress.

\section{Other Age-Related Diseases}

One of the most challenging problems in gerontology is to account for the age dependency of diseases whose incidence increases with age. As indicated above, at least for Alzheimer's disease, the age dependency can be explained at 
least in part by the increase in oxidative stress with age, which in our view can in turn be accounted for by glucose hysteresis. In fact, it is plausible to hypothesize that the dependence of most age-related diseases (except, as indicated above, possibly cancer) can be accounted for by an age-related increase in oxidative stress. For example, Huntington's disease appears to be due to a reduction in the utilization of ETC complex II [135]. Furthermore, dietary restriction substantially ameliorates symptoms in a mouse transgenic model of Huntington's disease [136]. We therefore propose that the increased penetrance of the Huntington's disease gene with age is due to a gradual reduction in the utilization of complex II in neurons during aging, secondary to glucose hysteresis, which in patients with Huntington's disease becomes lethal due to a preexisting impairment in complex II.

With regard to metabolic diseases, while it is clear how glucose hysteresis would account for age-related increases in diabetic complications, it is not so evident how this mechanism would account for the increased incidence in (type 2) diabetes with age. Type 2 diabetes is caused by the development of insulin resistance, usually accompanied by increased insulin secretion, eventually followed by pancreatic decompensation [12]. Oxidative stress plays a causal role in multiple forms of insulin resistance, many of which can be ameliorated by antioxidant treatments [138]. Similarly oxidative stress is implicated in pancreatic $\beta$-cell impairments [139]. Thus it is clear that increased oxidative stress during aging, secondary to glucose hysteresis, could plausibly account for the increased incidence of type II diabetes.

\section{Testing the Hypothesis: Reversibility of Senescence}

Although a substantial array of evidence supports that glucose hysteresis mediates at least part of the effects of dietary restriction, the hypothesis is nevertheless still subject to falsifiability. For example, the hypothesis predicts that factors which mediate effects of glucose on gene expression also mediate at least some of the effects of dietary restriction on gene expression. The hypothesis further predicts that manipulations that block effects of hypoglycemia on gene expression would also block at least some effects of dietary restriction on gene expression, and, more importantly, would attenuate beneficial effects of dietary restriction. For example, it may be possible to block effects of hypoglycemia on gene expression by ablating specific transcriptional factors or cofactors [140]. If blocking hypoglycemia-induced gene expression fails to block beneficial effects of dietary restriction, this would effectively falsify the glucose switch hypothesis.

Another obvious prediction is that reduction of plasma glucose by, for exam-

ple, transgenic expression of a glucose transporter, to the same extent as is 
observed with dietary restriction, should mimic effects of dietary restriction without caloric restriction. While this would indeed constitute a test of the hypothesis, there would be two caveats in interpreting these results. First, as indicated above, considerable evidence suggests that glucose signaling as well as the toxic effects of glucose are mediated by the production of NADH. If reduction of plasma glucose is accompanied by an increase in lactate, and lactate is used as an alternative fuel for glucose, lactate would plausibly produce the same levels of NADH as glucose, and therefore might prevent the beneficial effects of reduced glucose. This could be assessed by examining the expression of genes regulated by glucose: if hypoglycemia-induced genes are not induced by a reduction in plasma glucose, this would suggest that some compensatory mechanism, likely lactate, is preventing the beneficial effects of lower plasma glucose. Second, as also described above, some evidence suggests that the total 24-hour RQ is not reduced by dietary restriction and, if so, we would argue that the protective effect arises from reducing the total amount of time that tissues are predominantly using glucose as a fuel. If so, simply reducing total exposure to glucose may not be adequate to reproduce the extended period of time that cells are protected by predominant $\beta$-oxidation. If so, a test of the theory would require reproducing the pattern of RQ produced by dietary restriction, possibly using inducible promoters.

Another implication of the hypothesis is that it may be possible to reverse age-related impairments by producing carefully controlled hypoglycemia at levels lower than can be produced by optimum dietary restriction. Dietary restriction at $50 \%$ ad libitum levels, about the most restriction compatible with extended life, only reduces plasma glucose to around $4.5 \mathrm{~mm}$. However, counterregulatory and other protective responses are not activated until lower glucose levels of $3.6 \mathrm{~mm}$ or possibly even lower are reached, whereas cognitive impairments are not observed until much lower levels yet, around $2.6 \mathrm{~mm}$. Therefore there is a potentially safe range of plasma glucose that would allow the production of even more potent beneficial effects than are produced by dietary restriction. The hysteretic behavior of the lac operon suggests that even transient repetitive reductions in glucose could reverse the proglycolytic glucose switch transcriptional state, thereby reversing the increase in glycolysis, oxidative damage and tumor burden. Studies to assess this hypothesis are currently under way.

\section{References}

1 Masoro EJ, McCarter RJ, Katz MS, McMahan CA: Dietary restriction alters characteristics of glucose fuel use. J Gerontol 1992;47:B202-B208. 
2 Lee CK, Allison DB, Brand J, Weindruch R, Prolla TA: Transcriptional profiles associated with aging and middle age-onset caloric restriction in mouse hearts. Proc Natl Acad Sci USA 2002; 99:14988-14993.

3 Lin SJ, Kaeberlein M, Andalis AA, Sturtz LA, Defossez PA, Culotta VC, Fink GR, Guarente L: Calorie restriction extends Saccharomyces cerevisiae lifespan by increasing respiration. Nature 2002;418:344-348.

4 Lewis M: The lac repressor. C R Biol 2005;328:521-548.

5 DeRisi JL, Iyer VR, Brown PO: Exploring the metabolic and genetic control of gene expression on a genomic scale. Science 1997;278:680-686.

6 Roche E, Assimacopoulos-Jeannet F, Witters LA, Perruchoud B, Yaney G, Corkey B, Asfari M, Prentki M: Induction by glucose of genes coding for glycolytic enzymes in a pancreatic beta-cell line (INS-1). J Biol Chem 1997;272:3091-3098.

7 Abbot EL, McCormack JG, Reynet C, Hassall DG, Buchan KW, Yeaman SJ: Diverging regulation of pyruvate dehydrogenase kinase isoform gene expression in cultured human muscle cells. FEBS J 2005;272:3004-3014.

8 Pilkis SJ, Granner DK: Molecular physiology of the regulation of hepatic gluconeogenesis and glycolysis. Annu Rev Physiol 1992;54:885-909.

9 Carlson M: Glucose repression in yeast. Curr Opin Microbiol 1999;2:202-207.

10 Ronne H: Glucose repression in fungi. Trends Genet 1995;11:12-17.

11 Ruderman NB, Saha AK, Vavvas D, Witters LA: Malonyl-CoA, fuel sensing, and insulin resistance. Am J Physiol 1999;276:E1-E18.

12 Mobbs CV: Neurohumoral hysteresis as a mechanism for senescence: comparative aspects; in Scanes CG, Schriebman MP (eds): Development, Maturation, and Senescence of the Neuroendocrine System. New York, Academic Press, 1989, pp 223-252.

13 Mobbs CV: Neurotoxic effects of estrogen, glucose, and glucocorticoids: neurohumoral hysteresis and its pathological consequences during aging. Rev Biol Res Aging 1990;4:201-228.

14 Mobbs CV: Genetic influences on glucose neurotoxicity, aging, and diabetes: a possible role for glucose hysteresis. Genetica 1993;91:239-253.

15 Mobbs CV: Molecular hysteresis: residual effects of hormones and glucose on genes during aging. Neurobiol Aging 1994;15:523-534.

16 Pfaff DW, Brooks PJ, Funabashi T, Pfaus JG, Mobbs CV: Gene memory in neuroendocrine and behavioural systems. Ciba Found Symp 1992;168:165-183.

17 Burch JB, Weintraub H: Temporal order of chromatin structural changes associated with activation of the major chicken vitellogenin gene. Cell 1983;33:65-76.

18 Ringrose L, Paro R: Epigenetic regulation of cellular memory by the Polycomb and Trithorax group proteins. Annu Rev Genet 2004;38:413-443.

19 Ozbudak EM, Thattai M, Lim HN, Shraiman BI, Van Oudenaarden A: Multistability in the lactose utilization network of Escherichia coli. Nature 2004;427:737-740.

20 Laurent M, Charvin G, Guespin-Michel J: Bistability and hysteresis in epigenetic regulation of the lactose operon: since Delbruck, a long series of ignored models. Cell Mol Biol (Noisy-le-Grand) 2005;51:583-594.

21 Roy S, Sala R, Cagliero E, Lorenzi M: Overexpression of fibronectin induced by diabetes or high glucose: phenomenon with a memory. Proc Natl Acad Sci USA 1990;87:404-408.

22 Nathan DM, Cleary PA, Backlund JY, Genuth SM, Lachin JM, Orchard TJ, Raskin P, Zinman B: Intensive diabetes treatment and cardiovascular disease in patients with type 1 diabetes. $\mathrm{N}$ Engl $\mathrm{J}$ Med 2005;353:2643-2653.

23 Dillin A, Hsu AL, Arantes-Oliveira N, Lehrer-Graiwer J, Hsin H, Fraser AG, Kamath RS, Ahringer J, Kenyon C: Rates of behavior and aging specified by mitochondrial function during development. Science 2002;298:2398-2401.

24 Lee SS, Lee RY, Fraser AG, Kamath RS, Ahringer J, Ruvkun G: A systematic RNAi screen identifies a critical role for mitochondria in C. elegans longevity. Nat Genet 2003;33:40-48.

25 Hamilton B, Dong Y, Shindo M, Liu W, Odell I, Ruvkun G, Lee SS: A systematic RNAi screen for longevity genes in C. elegans. Genes Dev 2005;19:1544-1555.

26 Hansen M, Hsu AL, Dillin A, Kenyon C: New genes tied to endocrine, metabolic, and dietary regulation of lifespan from a Caenorhabditis elegans genomic RNAi screen. PLos Genet 2005;1:119-128. 
27 Ishii N, Fujii M, Hartman PS, Tsuda M, Yasuda K, Senoo-Matsuda N, Yanase S, Ayusawa D, Suzuki K: A mutation in succinate dehydrogenase cytochrome b causes oxidative stress and ageing in nematodes. Nature 1998;394:694-697.

28 Senoo-Matsuda N, Hartman PS, Akatsuka A, Yoshimura S, Ishii N: A complex II defect affects mitochondrial structure, leading to ced-3- and ced-4-dependent apoptosis and aging. J Biol Chem 2003;278:22031-22036.

29 Herrero A, Barja G: Localization of the site of oxygen radical generation inside the complex I of heart and nonsynaptic brain mammalian mitochondria. J Bioenerg Biomembr 2000;32: 609-615.

30 Lenaz G: The mitochondrial production of reactive oxygen species: mechanisms and implications in human pathology. IUBMB Life 2001;52:159-164.

31 Barja G: Aging in vertebrates, and the effect of caloric restriction: a mitochondrial free radical production-DNA damage mechanism? Biol Rev Camb Philos Soc 2004;79:235-251.

32 Senoo-Matsuda N, Yasuda K, Tsuda M, Ohkubo T, Yoshimura S, Nakazawa H, Hartman PS, Ishii N: A defect in the cytochrome b large subunit in complex II causes both superoxide anion overproduction and abnormal energy metabolism in Caenorhabditis elegans. J Biol Chem 2001;276: 41553-41558.

33 Lakowski B, Hekimi S: Determination of life-span in Caenorhabditis elegans by four clock genes. Science 1996;272:1010-1013.

34 Jonassen T, Larsen PL, Clarke CF: A dietary source of coenzyme Q is essential for growth of longlived Caenorhabditis elegans clk-1 mutants. Proc Natl Acad Sci USA 2001;98:421-426.

35 Branicky R, Benard C, Hekimi S: clk-1, mitochondria, and physiological rates. Bioessays 2000; 22:48-56.

36 Braeckman BP, Houthoofd K, Brys K, Lenaerts I, De Vreese A, Van Eygen S, Raes H, Vanfleteren JR: No reduction of energy metabolism in Clk mutants. Mech Ageing Dev 2002;123:1447-1456.

37 Kayser EB, Sedensky MM, Morgan PG, Hoppel CL: Mitochondrial oxidative phosphorylation is defective in the long-lived mutant clk-1. J Biol Chem 2004;279:54479-54486.

38 Nemoto S, Combs CA, French S, Ahn BH, Fergusson MM, Balaban RS, Finkel T: The mammalian longevity-associated gene product p66shc regulates mitochondrial metabolism. J Biol Chem 2006;281:10555-10560.

39 Tanaka M, Gong J, Zhang J, Yamada Y, Borgeld HJ, Yagi K: Mitochondrial genotype associated with longevity and its inhibitory effect on mutagenesis. Mech Ageing Dev 2000;116:65-76.

40 Lakowski B, Hekimi S: The genetics of caloric restriction in Caenorhabditis elegans. Proc Natl Acad Sci USA 1998;95:13091-13096.

41 Houthoofd K, Braeckman BP, Lenaerts I, Brys K, De Vreese A, Van Eygen S, Vanfleteren JR: No reduction of metabolic rate in food restricted Caenorhabditis elegans. Exp Gerontol 2002;37: 1359-1369.

42 Houthoofd K, Braeckman BP, Lenaerts I, Brys K, De Vreese A, Van Eygen S, Vanfleteren JR: Axenic growth up-regulates mass-specific metabolic rate, stress resistance, and extends life span in Caenorhabditis elegans. Exp Gerontol 2002;37:1371-1378.

43 McCarter R, Masoro EJ, Yu BP: Does food restriction retard aging by reducing the metabolic rate? Am J Physiol 1985;248:E488-E490.

44 Johnson TE, Cypser J, de Castro E, de Castro S, Henderson S, Murakami S, Rikke B, Tedesco P, Link C: Gerontogenes mediate health and longevity in nematodes through increasing resistance to environmental toxins and stressors. Exp Gerontol 2000;35:687-694.

45 Obici S, Feng Z, Tan J, Liu L, Karkanias G, Rossetti L: Central melanocortin receptors regulate insulin action. J Clin Invest 2001;108:1079-1085.

46 Sohal RS, Weindruch R: Oxidative stress, caloric restriction, and aging. Science 1996;273:59-63.

47 Lass A, Sohal BH, Weindruch R, Forster MJ, Sohal RS: Caloric restriction prevents age-associated accrual of oxidative damage to mouse skeletal muscle mitochondria. Free Radic Biol Med 1998;25: 1089-1097.

48 Desai VG, Weindruch R, Hart RW, Feuers RJ: Influences of age and dietary restriction on gastrocnemius electron transport system activities in mice. Arch Biochem Biophys 1996;333:145-151. 
49 Gredilla R, Sanz A, Lopez-Torres M, Barja G: Caloric restriction decreases mitochondrial free radical generation at complex I and lowers oxidative damage to mitochondrial DNA in the rat heart. Faseb J 2001;15:1589-1591.

50 Lopez-Torres M, Gredilla R, Sanz A, Barja G: Influence of aging and long-term caloric restriction on oxygen radical generation and oxidative DNA damage in rat liver mitochondria. Free Radic Biol Med 2002;32:882-889.

51 Sanz A, Caro P, Ibanez J, Gomez J, Gredilla R, Barja G: Dietary restriction at old age lowers mitochondrial oxygen radical production and leak at complex I and oxidative DNA damage in rat brain. J Bioenerg Biomembr 2005;37:83-90.

52 Kayo T, Allison DB, Weindruch R, Prolla TA: Influences of aging and caloric restriction on the transcriptional profile of skeletal muscle from rhesus monkeys. Proc Natl Acad Sci USA 2001;98: 5093-5098.

53 Salway JG: Metabolism at a Glance. Oxford, Blackwell, 1994.

54 Lee CK, Weindruch R, Prolla TA: Gene-expression profile of the ageing brain in mice. Nat Genet 2000;25:294-297.

55 Hagopian K, Ramsey JJ, Weindruch R: Influence of age and caloric restriction on liver glycolytic enzyme activities and metabolite concentrations in mice. Exp Gerontol 2003;38:253-266.

56 Lee CK, Pugh TD, Klopp RG, Edwards J, Allison DB, Weindruch R, Prolla TA: The impact of $\alpha-$ lipoic acid, coenzyme $\mathrm{Q}_{10}$ and caloric restriction on life span and gene expression patterns in mice. Free Radic Biol Med 2004;36:1043-1057.

57 Kimura KD, Tissenbaum HA, Liu Y, Ruvkun G: daf-2, an insulin receptor-like gene that regulates longevity and diapause in Caenorhabditis elegans. Science 1997;277:942-946.

58 Brown-Borg HM, Borg KE, Meliska CJ, Bartke A: Dwarf mice and the ageing process. Nature 1996;384:33.

59 Tatar M, Bartke A, Antebi A: The endocrine regulation of aging by insulin-like signals. Science 2003;299:1346-1351.

60 Houthoofd K, Braeckman BP, Johnson TE, Vanfleteren JR: Life extension via dietary restriction is independent of the Ins/IGF-1 signalling pathway in Caenorhabditis elegans. Exp Gerontol 2003; 38:947-954.

61 Bartke A, Wright JC, Mattison JA, Ingram DK, Miller RA, Roth GS: Extending the lifespan of long-lived mice. Nature 2001;414:412.

62 Clancy DJ, Gems D, Hafen E, Leevers SJ, Partridge L: Dietary restriction in long-lived dwarf flies. Science 2002;296:319.

63 Cerami A: Hypothesis: glucose as a mediator of aging. J Am Geriatr Soc 1985;33:626-634.

64 Asif M, Egan J, Vasan S, Jyothirmayi GN, Masurekar MR, Lopez S, Williams C, Torres RL, Wagle D, Ulrich P, Cerami A, Brines M, Regan TJ: An advanced glycation endproduct cross-link breaker can reverse age-related increases in myocardial stiffness. Proc Natl Acad Sci USA 2000;97: 2809-2813.

65 Rolo AP, Palmeira CM: Diabetes and mitochondrial function: role of hyperglycemia and oxidative stress. Toxicol Appl Pharmacol 2006;212:167-178.

66 Wallace DC: A mitochondrial paradigm of metabolic and degenerative diseases, aging, and cancer: a dawn for evolutionary medicine. Annu Rev Genet 2005;39:359-407.

67 Hansson A, Hance N, Dufour E, Rantanen A, Hultenby K, Clayton DA, Wibom R, Larsson NG: A switch in metabolism precedes increased mitochondrial biogenesis in respiratory chain-deficient mouse hearts. Proc Natl Acad Sci USA 2004;101:3136-3141.

68 Gruenewald DA, Matsumoto AM: Age-related decrease in proopiomelanocortin gene expression in the arcuate nucleus of the male rat brain. Neurobiol Aging 1991;12:113-121.

69 Lloyd JM, Scarbrough K, Weiland NG, Wise PM: Age-related changes in proopiomelanocortin (POMC) gene expression in the periarcuate region of ovariectomized rats. Endocrinology 1991;129:1896-1902.

70 Nelson JF, Bender M, Schacter BS: Age-related changes in proopiomelanocortin messenger ribonucleic acid levels in hypothalamus and pituitary of female C57B1/6J mice. Endocrinology 1988; 123:340-344.

71 Abel TW, Rance NE: Proopiomelanocortin gene expression is decreased in the infundibular nucleus of postmenopausal women. Brain Res Mol Brain Res 1999;69:202-208. 
Abel TW, Rance NE: Stereologic study of the hypothalamic infundibular nucleus in young and older women. J Comp Neurol 2000;424:679-688.

73 Abel TW, Voytko ML, Rance NE: The effects of hormone replacement therapy on hypothalamic neuropeptide gene expression in a primate model of menopause. J Clin Endocrinol Metab 1999;84: 2111-2118.

74 Mizuno TM, Kleopoulos SP, Bergen HT, Roberts JL, Priest CA, Mobbs CV: Hypothalamic proopiomelanocortin mRNA is reduced by fasting and in ob/ob and $\mathrm{db} / \mathrm{db}$ mice, but is stimulated by leptin. Diabetes 1998;47:294-297.

75 Bergen HT, Mizuno TM, Taylor J, Mobbs CV: Hyperphagia and weight gain after gold-thioglucose: relation to hypothalamic neuropeptide Y and proopiomelanocortin. Endocrinology 1998;139: 4483-4488

76 Ibrahim N, Bosch MA, Smart JL, Qiu J, Rubinstein M, Ronnekleiv OK, Low MJ, Kelly MJ: Hypothalamic proopiomelanocortin neurons are glucose responsive and express K(ATP) channels. Endocrinology 2003;144:1331-1340.

77 Mizuno TM, Kelly K, Pasinetti GM, Roberts JL, Mobbs CV: Transgenic neuronal expression of proopiomelanocortin attenuates fasting-induced hyperphagia and reverses metabolic impairments in leptin-deficient obese mice. Diabetes 2003;52:2675-2683.

78 Matschinsky FM: Banting Lecture 1995 - A lesson in metabolic regulation inspired by the glucokinase glucose sensor paradigm. Diabetes 1996;45:223-241.

79 Matschinsky FM, Collins HW: Essential biochemical design features of the fuel-sensing system in pancreatic $\beta$-cells. Chem Biol 1997;4:249-257.

80 Matschinsky FM, Glaser B, Magnuson MA: Pancreatic $\beta$-cell glucokinase: closing the gap between theoretical concepts and experimental realities. Diabetes 1998;47:307-315.

81 Matschinsky F, Liang Y, Kesavan P, Wang L, Froguel P, Velho G, Cohen D, Permutt MA, Tanizawa Y, Jetton TL, et al: Glucokinase as pancreatic beta cell glucose sensor and diabetes gene. J Clin Invest 1993;92:2092-2098.

82 Matschinsky FM: Glucokinase as glucose sensor and metabolic signal generator in pancreatic $\beta$-cells and hepatocytes. Diabetes 1990;39:647-652.

83 Yang XJ, Kow LM, Funabashi T, Mobbs CV: Hypothalamic glucose sensor: similarities to and differences from pancreatic $\beta$-cell mechanisms. Diabetes 1999;48:1763-1672.

84 Jetton TL, Liang Y, Pettepher CC, Zimmerman EC, Cox FG, Horvath K, Matschinsky FM, Magnuson MA: Analysis of upstream glucokinase promoter activity in transgenic mice and identification of glucokinase in rare neuroendocrine cells in the brain and gut. J Biol Chem 1994;269: 3641-3654.

85 Lynch RM, Tompkins LS, Brooks HL, Dunn-Meynell AA, Levin BE: Localization of glucokinase gene expression in the rat brain. Diabetes 2000;49:693-700.

86 Eto K, Tsubamoto Y, Terauchi Y, Sugiyama T, Kishimoto T, Takahashi N, Yamauchi N, Kubota N, Murayama S, Aizawa T, Akanuma Y, Aizawa S, Kasai H, Yazaki Y, Kadowaki T: Role of NADH shuttle system in glucose-induced activation of mitochondrial metabolism and insulin secretion. Science 1999;283:981-985.

87 Lin SJ, Defossez PA, Guarente L: Requirement of NAD and SIR2 for life-span extension by calorie restriction in Saccharomyces cerevisiae. Science 2000;289:2126-2128.

88 Mastaitis JW, Cheng H, Sealfon SC, Mobbs CV: Acute induction of gene expression in brain and liver by insulin-induced hypoglycemia. Diabetes 2005;54:952-958.

89 Mobbs CV, Yen K, Mastaitis J, Nguyen H, Watson E, Wurmbach E, Sealfon SC, Brooks A, Salton SR: Mining microarrays for metabolic meaning: nutritional regulation of hypothalamic gene expression. Neurochem Res 2004;29:1093-1103.

90 Ward WF: Food restriction enhances the proteolytic capacity of the aging rat liver. J Gerontol 1988;43:B121-B124.

91 Salvemini F, Franze A, Iervolino A, Filosa S, Salzano S, Ursini MV: Enhanced glutathione levels and oxidoresistance mediated by increased glucose-6-phosphate dehydrogenase expression. J Biol Chem 1999;274:2750-2757.

92 Ursini MV, Parrella A, Rosa G, Salzano S, Martini G: Enhanced expression of glucose-6-phosphate dehydrogenase in human cells sustaining oxidative stress. Biochem J 1997;323:801-806. 
93 Filosa S, Fico A, Paglialunga F, Balestrieri M, Crooke A, Verde P, Abrescia P, Bautista JM, Martini G: Failure to increase glucose consumption through the pentose-phosphate pathway results in the death of glucose-6-phosphate dehydrogenase gene-deleted mouse embryonic stem cells subjected to oxidative stress. Biochem J 2003;370:935-943.

94 Luckinbill LS, Riha V, Rhine S, Grudzien TA: The role of glucose-6-phosphate dehydrogenase in the evolution of longevity in Drosophila melanogaster. Heredity 1990;65:29-38.

95 Jo SH, Son MK, Koh HJ, Lee SM, Song IH, Kim YO, Lee YS, Jeong KS, Kim WB, Park JW, Song BJ, Huh TL, Huhe TL: Control of mitochondrial redox balance and cellular defense against oxidative damage by mitochondrial NADP+-dependent isocitrate dehydrogenase. J Biol Chem 2001;276: $16168-16176$.

96 Kil IS, Lee YS, Bae YS, Huh TL, Park JW: Modulation of NADP(+)-dependent isocitrate dehydrogenase in aging. Redox Rep 2004;9:271-277.

97 Da Cunha GL, de Oliveira AK: Citric acid cycle: a mainstream metabolic pathway influencing life span in Drosophila melanogaster? Exp Gerontol 1996;31:705-715.

98 Sreekumar R, Unnikrishnan J, Fu A, Nygren J, Short KR, Schimke J, Barazzoni R, Nair KS: Effects of caloric restriction on mitochondrial function and gene transcripts in rat muscle. Am $\mathrm{J}$ Physiol Endocrinol Metab 2002;283:E38-E43.

99 Agarwal S, Sharma S, Agrawal V, Roy N: Caloric restriction augments ROS defense in S. cerevisiae, by a Sir2p independent mechanism. Free Radic Res 2005;39:55-62.

100 Van Remmen H, Ikeno Y, Hamilton M, Pahlavani M, Wolf N, Thorpe SR, Alderson NL, Baynes JW, Epstein CJ, Huang TT, Nelson J, Strong R, Richardson A: Life-long reduction in MnSOD activity results in increased DNA damage and higher incidence of cancer but does not accelerate aging. Physiol Genomics 2003;16:29-37.

101 Brownlee M: Biochemistry and molecular cell biology of diabetic complications. Nature 2001;414: 813-820.

102 Zhang Y, Cao R, Wang L, Jones RS: Mechanism of Polycomb group gene silencing. Cold Spring Harb Symp Quant Biol 2004;69:309-317.

103 Acker T, Plate KH: Hypoxia and hypoxia inducible factors (HIF) as important regulators of tumor physiology. Cancer Treat Res 2004;117:219-248.

104 Rising R, Tataranni PA, Snitker S, Ravussin E: Decreased ratio of fat to carbohydrate oxidation with increasing age in Pima Indians. J Am Coll Nutr 1996;15:309-312.

105 Lee CK, Klopp RG, Weindruch R, Prolla TA: Gene expression profile of aging and its retardation by caloric restriction. Science 1999;285:1390-1393.

106 Zinke I, Schutz CS, Katzenberger JD, Bauer M, Pankratz MJ: Nutrient control of gene expression in Drosophila: microarray analysis of starvation and sugar-dependent response. Embo J 2002;21: 6162-6173.

107 Higami Y, Pugh TD, Page GP, Allison DB, Prolla TA, Weindruch R: Adipose tissue energy metabolism: altered gene expression profile of mice subjected to long-term caloric restriction. Faseb $\mathrm{J}$ 2004; $18: 415-417$.

108 Orentreich N, Matias JR, DeFelice A, Zimmerman JA: Low methionine ingestion by rats extends life span. J Nutr 1993;123:269-274.

109 Miller RA, Buehner G, Chang Y, Harper JM, Sigler R, Smith-Wheelock M: Methionine-deficient diet extends mouse lifespan, slows immune and lens aging, alters glucose, $\mathrm{T}_{4}$, IGF-I and insulin levels, and increases hepatocyte MIF levels and stress resistance. Aging Cell 2005;4: 119-125.

110 Mair W, Piper MD, Partridge L: Calories do not explain extension of life span by dietary restriction in Drosophila. PLos Biol 2005;3:e223.

111 Masoro EJ, Iwasaki K, Gleiser CA, McMahan CA, Seo EJ, Yu BP: Dietary modulation of the progression of nephropathy in aging rats: an evaluation of the importance of protein. Am J Clin Nutr 1989;49:1217-1227.

112 Iwasaki K, Gleiser CA, Masoro EJ, McMahan CA, Seo EJ, Yu BP: Influence of the restriction of individual dietary components on longevity and age-related disease of Fischer rats: the fat component and the mineral component. J Gerontol 1988;43:B13-B21. 
113 Anson RM, Guo Z, de Cabo R, Iyun T, Rios M, Hagepanos A, Ingram DK, Lane MA, Mattson MP: Intermittent fasting dissociates beneficial effects of dietary restriction on glucose metabolism and neuronal resistance to injury from calorie intake. Proc Natl Acad Sci USA 2003;100:6216-6220.

114 Semenza GL, Artemov D, Bedi A, Bhujwalla Z, Chiles K, Feldser D, Laughner E, Ravi R, Simons J, Taghavi P, Zhong H: 'The metabolism of tumours': 70 years later. Novartis Found Symp 2001;240:251-260, discussion 260-264.

115 Altenberg B, Greulich KO: Genes of glycolysis are ubiquitously overexpressed in 24 cancer classes. Genomics 2004;84:1014-1020.

$116 \mathrm{Xu}$ RH, Pelicano H, Zhou Y, Carew JS, Feng L, Bhalla KN, Keating MJ, Huang P: Inhibition of glycolysis in cancer cells: a novel strategy to overcome drug resistance associated with mitochondrial respiratory defect and hypoxia. Cancer Res 2005;65:613-621.

117 Izyumov DS, Avetisyan AV, Pletjushkina OY, Sakharov DV, Wirtz KW, Chernyak BV, Skulachev VP: 'Wages of fear': transient threefold decrease in intracellular ATP level imposes apoptosis. Biochim Biophys Acta 2004;1658:141-147.

118 Wan R, Camandola S, Mattson MP: Intermittent fasting and dietary supplementation with 2deoxy-D-glucose improve functional and metabolic cardiovascular risk factors in rats. Faseb J 2003; 17:1133-1134.

119 Perez-Campo R, Lopez-Torres M, Cadenas S, Rojas C, Barja G: The rate of free radical production as a determinant of the rate of aging: evidence from the comparative approach. J Comp Physiol B 1998;168:149-158.

120 Barja G, Herrero A: Localization at complex I and mechanism of the higher free radical production of brain nonsynaptic mitochondria in the short-lived rat than in the longevous pigeon. $\mathrm{J}$ Bioenerg Biomembr 1998;30:235-243.

121 Barja G, Herrero A: Oxidative damage to mitochondrial DNA is inversely related to maximum life span in the heart and brain of mammals. Faseb J 2000;14:312-318.

122 Sohal RS, Sohal BH, Brunk UT: Relationship between antioxidant defenses and longevity in different mammalian species. Mech Ageing Dev 1990;53:217-227.

123 Ishii N, Goto S, Hartman PS: Protein oxidation during aging of the nematode Caenorhabditis elegans. Free Radic Biol Med 2002;33:1021-1025.

124 Nicolle MM, Gonzalez J, Sugaya K, Baskerville KA, Bryan D, Lund K, Gallagher M, McKinney $\mathrm{M}$ : Signatures of hippocampal oxidative stress in aged spatial learning-impaired rodents. Neuroscience 2001;107:415-431.

125 Zainal TA, Oberley TD, Allison DB, Szweda LI, Weindruch R: Caloric restriction of rhesus monkeys lowers oxidative damage in skeletal muscle. Faseb J 2000;14:1825-1836.

126 Sindelar DK, Ste Marie L, Miura GI, Palmiter RD, McMinn JE, Morton GJ, Schwartz MW: Neuropeptide $\mathrm{Y}$ is required for hyperphagic feeding in response to neuroglucopenia. Endocrinology 2004;145:3363-3368.

127 Tkacs NC, Dunn-Meynell AA, Levin BE: Presumed apoptosis and reduced arcuate nucleus neuropeptide $\mathrm{Y}$ and pro-opiomelanocortin mRNA in non-coma hypoglycemia. Diabetes 2000;49: $820-826$.

128 Cryer PE: Hierarchy of physiological responses to hypoglycemia: relevance to clinical hypoglycemia in type I (insulin dependent) diabetes mellitus. Horm Metab Res 1997;29:92-96.

129 Jacobson L, Ansari T, McGuinness OP: Counterregulatory deficits occur within $24 \mathrm{~h}$ of a single hypoglycemic episode in conscious, unrestrained, chronically cannulated mice. Am J Physiol Endocrinol Metab 2006;290:E678-E684.

130 Cryer PE: Hypoglycemia-associated autonomic failure in insulin-dependent diabetes mellitus. Adv Pharmacol 1998;42:620-622.

131 Wen Y, Gu J, Li SL, Reddy MA, Natarajan R, Nadler JL: Elevated glucose and diabetes promote interleukin 12 cytokine gene expression in mouse macrophages. Endocrinology 2006;147: 2518-2525.

132 Masoro EJ: Caloric restriction and aging: controversial issues. J Gerontol A Biol Sci Med Sci 2006;61:14-19.

133 Mohmmad Abdul H, Sultana R, Keller JN, St Clair DK, Markesbery WR, Butterfield DA: Mutations in amyloid precursor protein and presenilin-1 genes increase the basal oxidative stress in murine neuronal cells and lead to increased sensitivity to oxidative stress mediated by amyloid 
beta-peptide (1-42), HO and kainic acid: implications for Alzheimer's disease. J Neurochem 2006;96:1322-1335.

134 Moreira PI, Honda K, Liu Q, Santos MS, Oliveira CR, Aliev G, Nunomura A, Zhu X, Smith MA, Perry G: Oxidative stress: the old enemy in Alzheimer's disease pathophysiology. Curr Alzheimer Res 2005;2:403-408.

135 Benchoua A, Trioulier Y, Zala D, Gaillard MC, Lefort N, Dufour N, Saudou F, Elalouf JM, Hirsch E, Hantraye P, Deglon N, Brouillet E: Involvement of mitochondrial complex II defects in neuronal death produced by N-terminus fragment of mutated huntingtin. Mol Biol Cell 2006;17: 1652-1663.

136 Duan W, Guo Z, Jiang H, Ware M, Li XJ, Mattson MP: Dietary restriction normalizes glucose metabolism and BDNF levels, slows disease progression, and increases survival in huntingtin mutant mice. Proc Natl Acad Sci USA 2003;100:2911-2916.

137 Gandhi S, Wood NW: Molecular pathogenesis of Parkinson's disease. Hum Mol Genet 2005;14: 2749-2755.

138 Houstis N, Rosen ED, Lander ES: Reactive oxygen species have a causal role in multiple forms of insulin resistance. Nature 2006;440:944-948.

139 Simmons RA, Suponitsky-Kroyter I, Selak MA: Progressive accumulation of mitochondrial DNA mutations and decline in mitochondrial function lead to $\beta$-cell failure. J Biol Chem 2005;280: 28785-28791.

140 Towle HC: Glucose as a regulator of eukaryotic gene transcription. Trends Endocrinol Metab 2005;16:489-494.

\section{Charles V. Mobbs, PhD}

Departments of Neuroscience and Geriatrics

Mount Sinai School of Medicine, Box 1639, 1 Gustave L. Levy Place

New York, NY 10029 (USA)

Tel. +1 212659 5929, Fax +1 212849 2510, E-Mail charles.mobbs@mssm.edu 